\title{
Arthralgia in 329 Patients Taking Aromatase Inhibitors
}

\author{
Yoshiya Horimoto Mitsue Saito Fujio Kasumi \\ Department of Breast Oncology, Juntendo University School of Medicine, Tokyo, Japan
}

\section{Key Words}

Arthralgia · Aromatase inhibitor - Breast cancer

\section{Summary}

Background: Arthralgia is common in post-menopausal women taking aromatase inhibitors. However, the underlying mechanism remains unknown. Patients and Methods: We retrospectively examined the records of outpatients taking aromatase inhibitors to ascertain the frequency and severity of arthralgia. Results: Among 329 patients taking aromatase inhibitors (anastrozole in 239 and exemestane in 90 patients), $27 \%$ had arthralgia. There were 51 patients (16\%) who switched from one aromatase inhibitor to another or quit aromatase inhibitor treatment. Arthralgia was the second most common reason for treatment changes in these 51 cases. In most cases, symptoms resolved after switching to a selective estrogen receptor modulator (SERM). We examined the relationships of arthralgia with other factors such as age, type of medication, prior treatments, and bone density. The arthralgia rate was significantly lower $(p<0.05)$ in patients with preceding endocrine therapy. No significant difference was detected between patients with versus patients without chemotherapy. Furthermore, there was no relationship between bone density and arthralgia. Conclusion: Our observations suggest SERM treatment combined with an aromatase inhibitor to be perhaps the most practical clinical solution to the problem of arthralgia.
Schlüsselwörter

Arthralgie · Aromatasehemmer · Brustkrebs

\section{Zusammenfassung}

Hintergrund: Arthralgie ist verbreitet bei Frauen in der Postmenopause, die mit Aromatasehemmern behandelt werden. Die Ursache dafür ist jedoch noch ungeklärt. Patienten und Methoden: Wir werteten Krankengeschichten von Aromatasehemmer-Patienten aus, um eine signifikante Korrelation zwischen der Einnahme von Aromatasehemmern und dem Auftreten von Arthralgien zu bestätigen. Ergebnisse: Von 329 Patienten, die Aromatasehemmer (239 Anastrozol und 90 Exemestan) einnahmen, litten 27\% unter Arthralgie. Darunter waren 51 Patienten (16\%), die den Aromatasehemmer wechselten oder die Behandlung abgebrochen haben. Arthralgie war der zweithäufigste Grund für den Therapiewechsel in den 51 Fällen. In den meisten Fällen wurden die Symptome dadurch behoben, dass die Therapie mit selektiven Östrogenrezeptormodulatoren (SERM) fortgesetzt wurde. Wir untersuchten die Zusammenhänge von Arthralgie mit Faktoren wie Alter, Art der Behandlung, frühere Behandlung sowie Knochendichte. Das Auftreten von Arthralgien war wesentlich geringer $(p<0.05)$ bei Patienten mit vorheriger Hormontherapie; Chemotherapie hatte jedoch keinen Einfluss. Es wurde kein Zusammenhang zwischen Knochendichte und Arthralgien festgestellt. Schlussfolgerung: Unsere Beobachtungen deuten darauf hin, dass eine SERM-Therapie mit anschließender Aromatasehemmer-Behandlung die vielversprechendste Behandlungsmethode für Arthralgien ist.

\section{KARGER}

Fax +497614520714

Information@Karger.de

www.karger.com (c) 2009 S. Karger GmbH, Freiburg

Accessible online at:

www.karger.com/brc

Yoshiya Horimoto, M.D.

Department of Breast Oncology, Juntendo University School of Medicine

2-1-1 Hongo, Bunkyo-ku

Tokyo, 113-0033, Japan

Tel. +81 3 3813-3111 ext 5855, Fax -3307

yoshiyahorimoto@hotmail.com 


\section{Introduction}

Arthralgia is common in post-menopausal women taking aromatase inhibitors (AIs). Some patients will quit taking an AI if their pain becomes severe. It is difficult to evaluate arthralgia as it shows variable manifestations. There are differences in the type of pain, which may or may not be constant, and different parts of the body can be affected. Moreover, the underlying mechanism remains unknown and no appropriate treatment has yet been established. Thus, patients have few choices and often endure the pain. We retrospectively examined the records of outpatients taking AIs for various periods to ascertain the frequency and severity of arthralgia. The relevant literature is also reviewed.

\section{Patients and Methods}

There were 422 patients who had taken AIs (anastrozole (ANA) or exemestane (EXE)) at our outpatient clinic during the 20-month period from January 2006 to August 2007. We excluded 93 cases because the administration or observation period was too short due to hospital transfer and various other factors. Letrozole had not been approved for use in patients in Japan at the time of this study.

We assessed 329 patients in detail for the severity of arthralgia based on subjective symptoms documented in their medical records. Their clinical courses were reviewed. Possible associations between symptom manifestation and factors such as age, type of medication, prior treatments, and bone density were also examined based on the data from medical records.

\section{Results}

Mean age at the time of investigation was 64 years (35-91 years). ANA was used in 239 cases, EXE in 90. 278 patients ( $84 \%$ of the total) received AIs as adjuvant treatment after surgery, $43(13 \%)$ for recurrent disease. 8 patients $(2 \%)$ treated with AIs refused surgery. The median observation period was 16 months (1-62 months). Arthralgia was noted in $27 \%$ (90 cases). The median period until arthralgia onset was 6 months ( 1 week-47 months) after starting AI treat- ment. The actual frequencies were not calculated, but symptoms that appeared to be related to AIs, besides arthralgia, were numbness of the hands and feet, hot flushes, muscle pain, edema, depression, sleeplessness, and fatigue.

There were 51 patients (16\% of the 329 subjects) who switched from one AI to another or quit AI treatment. The cause was disease progression in 26 cases $(51 \%$ of the 51 cases), arthralgia in $9(18 \%)$, tingling in the fingers in $3(6 \%)$, muscle pain in $3(6 \%)$, depression in $3(6 \%)$, and edema in $2(4 \%)$. The treatment details after arthralgia appearance in the 9 cases with arthralgia are shown in table 1.2 patients (22\% of the 9 ) were switched from one AI to another and 6 (67\%) were switched to a selective estrogen receptor modulator (SERM). In most cases, the symptoms resolved. All but 1 patient $(11 \%)$, who stopped taking AI, have been able to continue endocrine therapy to date.

Next, we examined relationships of arthralgia with other factors, including age, the type of AI, preceding chemotherapy and endocrine therapy, and the bone density index, all regarded as factors possibly associated with the occurrence of arthralgia (table 2). The arthralgia rate was significantly lower $(\mathrm{p}<0.05)$ in patients with prior endocrine therapy than in those who had never had endocrine treatment. As to prior endocrine therapies, SERM was used in 75 cases $(80 \%)$ while the remainder took another AI or a LH-RH (luteinizing hormone-releasing hormone) agonist. There were no significant differences in arthralgia occurrence rates between SERM and other endocrine treatments.

Because DEXA (dual energy X-ray absorptiometry) for bone mineral density (BMD) testing had been performed at several different times, we reexamined only the 47 cases $(34 \%$ of all DEXA performed) who had undergone this test within 6 months before or after starting an AI treatment. We detected no significant association between arthralgia and BMD. The details of 23 cases, examined twice during the observation period, are presented in figure 1.9 patients $(39 \%)$ were treated with bisphosphonates (BP) and the rest (61\%) was not. In the patients not given BP (average 14-month measurement interval), BMD decreased significantly $(\mathrm{p}<0.05)$. In contrast, BMD increased in the BP-treated group (13 months) $(\mathrm{p}<0.05)$.
Table 1. Nine cases which changed or quit treatment due to arthralgia

\begin{tabular}{llllll}
\hline Change & Cases & Course & Cases & Next medication & Cases \\
\hline AI $\rightarrow$ another AI & 2 & $\begin{array}{l}\text { improved } \\
\text { unchanged }\end{array}$ & 1 & EXE $\rightarrow$ ANA & 1 \\
& & ANA $\rightarrow$ EXE & 1 \\
AI $\rightarrow$ SERM & 6 & improved & $5^{\text {a }}$ & $\begin{array}{l}\text { AI } \rightarrow \text { TAM } \\
\text { AI } \rightarrow \text { TOR }\end{array}$ & 3 \\
& & unchanged & 1 & AI $\rightarrow$ TOR & 1 \\
\hline Quit & 1 & improved & 1 & & \\
\hline
\end{tabular}

$\mathrm{AI}=$ Aromatase inhibitor; SERM = selective estrogen receptor modulator; $\mathrm{EXE}=$ exemestane; ANA = anastrozole; TAM = tamoxifen; TOR = toremifen.

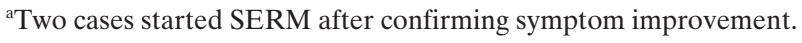




\section{Discussion}

According to several reports, the frequency of arthralgia in patients taking AIs is 16-36\% [1-4], and the rate in our institution was $27 \%$. Definitions of arthralgia differ among reports. Some describe stiffness and pain caused by arthritis as 'joint disorders', while others discuss these symptoms separately. 'Stiffness' might be regarded as distinct from arthralgia because the underlying mechanism is different. We considered stiffness to represent arthralgia in this study because patients were not thoroughly questioned about these symptoms in the

Table 2. Correlations between clinical factors and arthralgia

\begin{tabular}{|c|c|c|c|}
\hline & \multicolumn{2}{|c|}{ Arthralgia } & \multirow[t]{2}{*}{ p-value } \\
\hline & yes & no & \\
\hline \multicolumn{4}{|l|}{ Age, years } \\
\hline$<51$ & 6 & 9 & \multirow{4}{*}{ NS } \\
\hline $51-60$ & 38 & 89 & \\
\hline $61-70$ & 29 & 74 & \\
\hline$>70$ & 17 & 67 & \\
\hline \multicolumn{4}{|l|}{$A I$} \\
\hline ANA & 68 & 165 & \multirow[b]{2}{*}{ NS } \\
\hline EXE & 22 & 74 & \\
\hline \multicolumn{4}{|c|}{ Preceding chemotherapy } \\
\hline Yes & 46 & 97 & \multirow[b]{2}{*}{ NS } \\
\hline No & 43 & 136 & \\
\hline \multicolumn{4}{|c|}{ Preceding endocrine therapy } \\
\hline Yes & 18 & 76 & \multirow[b]{2}{*}{$<0.05$} \\
\hline No & 72 & 163 & \\
\hline \multicolumn{4}{|l|}{$D E X A$} \\
\hline Normal & 16 & 35 & \multirow{3}{*}{ NS } \\
\hline Decreased BMD & 23 & 42 & \\
\hline Osteoporosis & 3 & 19 & \\
\hline
\end{tabular}

$\mathrm{AI}=$ Aromatase inhibitor; ANA = anastrozole; $\mathrm{EXE}=$ exemestane; $\mathrm{DEXA}=$ dual energy X-ray absorptiometry; $\mathrm{BMD}=$ bone mineral density; NS = not significant (chi-square test). outpatient clinic. Stiffness of the hands was noted in at least 21 of the 90 patients $(23 \%)$ who complained of arthralgia. 3 patients $(3 \%)$ developed trigger fingers during the observation period. The possibility of AI causing trigger finger has been suggested [5]. Thus, we must pay attention to this symptom as well as carpal tunnel syndrome, the rate of which is increased sevenfold in patients taking AIs [6].

Direct questioning of patients is the most important means of evaluating arthralgia. However, consistent data are difficult to obtain. A symptom complaint can easily change according to timing, individual character factors, and how a question is asked. The figure of $27 \%$ obtained in this study might have been higher if the patients had been questioned in greater detail. However, it is important not to emphasize AI-associated arthralgia more than necessary and to keep in mind that tamoxifen (TAM) also reportedly causes arthralgia in 12-29\% of patients [1]. As to imaging approaches, a trial to evaluate arthralgia by measuring cartilage volume is presently underway [1]. Furthermore, as discussed below, arthralgia has also been evaluated by ultrasound (US) and magnetic resonance imaging (MRI) [5]. These modalities are clinically unrealistic as both are time-consuming and costly, while they are useful for studying underlying mechanisms. Moreover, pain scales, based on the difficulty of performing tasks or affected parts of the body, should also perhaps be developed.

There were no differences in arthralgia occurrence according to either age or the type of AI, i.e. non-steroidal versus steroidal, in this study (table 2). The possibility of chemotherapy damaging joints has also been raised $[3,4,7,8]$. However, Coleman et al. (ATAC trial) [9] found no difference in joint symptoms between patients with versus those without preceding chemotherapy. Thus, no consensus has yet been reached. No significant difference was detected in this study between patients with versus those without chemotherapy. There was a difference in the rate of arthralgia according to the presence of preceding endocrine therapy, with the medicated patients showing less arthralgia $(\mathrm{p}<0.05)$. We speculate that SERM
Fig. 1. Changes in bone density over time; $\mathrm{BP}=$ bisphosponate (oral).

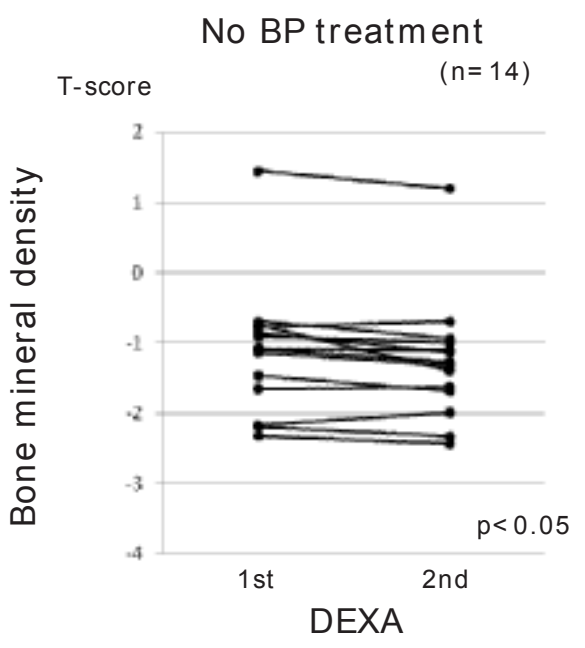

Breast Care 2009;4:319-323
BP treatment

$(n=9)$

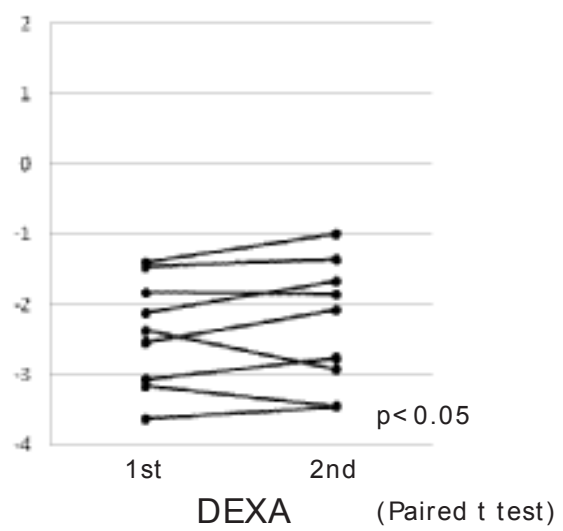


has a joint-protective action [8]. TAM was used by $80 \%$ of patients as preceding endocrine therapy. Recent endocrine therapies might suppress arthralgia onset in joints via preceding exposure to a low estrogen state. There is reportedly a relation between bone density and arthralgia, and Burstein [1] suggested that microfractures lead to pain. No such relationship was detected in this study. Bone density changes over time were demonstrated with sequential examinations. A bone density decrease was observed in the group not receiving BP while the BP-treated group showed an increase (fig. 1). However, we could not compare these groups directly because the BP administration periods were not the same.

Numerous aspects of the mechanisms underlying the occurrence of arthralgia remain uncertain [1, 2]. Morales et al. [5] examined the carpal joints of patients taking AIs by US and MRI. They noted the existence of a characteristic tendinitis. Fluid collection in the tendon sheath of the fingers, thickening of the sheath, and soft tissue edema were observed at high rates. Arthralgia generally involves the entire synovial membrane, joint capsule, perichondrial bone, and ligaments [10]. As underlying mechanisms, 2 pathways have been proposed: the central nervous system (CNS) and bone. Estrogen has an antinociceptive role in the CNS [10-12]. The pain threshold is lowered as estrogen decreases. Besides the direct effects of exogenous estrogen on nerve cells, these cells can also produce their own estrogen because they have aromatase [12]. The pathway involving bone functions is based on the premise that microfractures in the bone play a role in pain. Originally, estrogen was thought only to control bone metabolic turnover and to play a role in the healing of microfractures and suppression of local inflammatory reactions induced by such fractures. Pain is more likely to occur when these actions of estrogen are suppressed [1]. Estrogen receptors have been demonstrated at the synovial membranes of joints [13]. Thus, estrogen would influence synovial membrane functions such as the secretion of joint fluid. This is the main reason that joint stiffness develops as estrogen levels drop during AI treatment.

Various approaches to treating arthralgia have been attempted. Non-steroidal anti-inflammatory drugs (NSAID), acetaminophen, opioids, chondroitin, and capsaicin are widely used $[14,15]$. Besides these drug treatments, psychotherapy aimed at ameliorating stress and depression as well as physical therapy are common. Psychotherapy is useful because sleep disorders exacerbate pain (lowering the pain threshold) [1]. Physical therapy is also of value because the surrounding muscle can atrophy, and thereby increase the burden on joints, when movement is restricted by pain. However, no treatment is optimal for all patients and all are effective to some degree. Developing arthralgia treatments tailored to individual patients will allow prolonged AI administration. At present, patients often have little choice but to endure the arthralgia.
BP, a medication for osteoporosis, controls bone absorption by osteoclasts. BP might also suppress arthralgia indirectly [1, $11,14]$. Activated osteoclasts generally act in opposition to joint defense systems like the synovial membrane. Thus, suppressing osteoclast activity might protect joints and thereby relieve pain despite persistent low estrogen in the joint [16, 17]. Nakamura [18] indicated that worsening vertebral degeneration with excess weight could cause pain if bone strength is diminished. Assuming that BP increases bone density and reduces microfractures, arthralgia would improve. 30 of our patients had received BP treatment. Some had osteoporosis and others showed various degrees of bone density loss. However, no decrease in arthralgia occurrence was observed in this group. We need to prospectively reexamine this possible relationship, with standardization of the timing of AI initiation and arthralgia evaluation. Some patients will quit taking an AI if their arthralgia becomes severe. There is no consensus yet as to which medications should be tried after AI cessation. Symptoms occasionally improve when the patient switches from one AI to another [19]. There were also 2 patients in this study who were able to continue endocrine therapy by switching to another AI. It appears to be worthwhile to try switching, though a placebo effect could also exist. However, changing to another AI is not likely to be the most reasonable first alternative because the mechanism underlying symptom improvement is not well understood. Changing from an AI to a SERM is currently the most practical approach [1]. 5 of the 6 cases $(83 \%)$ in this study who changed from an AI to a SERM experienced symptom improvement (table 1). As noted above (table 2), patients with prior SERM treatment had a lower rate of arthralgia while on AI. Our observations suggest a course of SERM, followed by AI administration, to possibly produce the lowest rate of arthralgia. This is perhaps the best and quickest solution to the problem of arthralgia. The unquantifiable side effects of arthralgia cannot be adequately evaluated in a retrospective study such as this one. This issue must be addressed in a prospective study, and we are now launching such a project using novel metabolic markers.

In conclusion, patients with prior SERM treatment in this study had a lower rate of arthralgia while on AI. Most patients who complained of severe arthralgia and whose treatment was switched from an AI to a SERM experienced symptom improvement. Therefore, combining AI and SERM treatments may ameliorate arthralgic symptoms as well as improve AI compliance.

\section{Conflict of Interest}

There are no conflicts of interest in this study. 


\section{References}

1 Burstein HJ: Aromatase inhibitor-associated arthralgia syndrome. Breast 2007;16:223-234.

2 Donnellan PP, Douglas SL, Cameron DA, Leonard RC: Aromatase inhibitors and arthralgia. J Clin Oncol 2001;19:2767.

-3 Ohsako T, Inoue K, Nagamoto N, Yoshida Y, Nakahara O, Sakamoto N: Joint symptoms: a practical problem of anastrozole. Breast Cancer 2006;13: 284-288.

4 Okumura Y, Yamamoto Y, Kawasoe T, Kai K, Ibusuki M, Iwase H: Examination of arthralgia with aromatase inhibitors (in Japanese). Nyugan No Rinsyo 2005;20:418-419.

$>5$ Morales L, Pans S, Paridaens R, Westhovens R, Timmerman D, Verhaeghe J, Wildiers H, Leunen K, Amant F, Berteloot P, Smeets A, Limbergen EV, Weltens C, Bogaert WV, Smet L, Vergote I, Christiaens MR, Neven P: Debilitating musculoskeletal pain and stiffness with letrozole and exemestane: associated tenosynovial changes on magnetic resonance imaging. Breast Cancer Res Treat 2006;104: 87-91.

6 Coombes RC, Paridaens R, Jassem C, Van de Velde CJ, Delozier T, Jones SE, Hall E, Kilburn LS, Snowdon CF, Bliss JM: First mature analysis of the Intergroup Exemestane Study. J Clin Oncol (Meeting Abstracts) 2006;24:LBA 527.
Kim MJ, Ye YM, Park HS, Suh CH: Chemotherapy-related arthropathy. J Rheumatol 2006;33:13641368.

8 Crew KD, Greenlee H, Capodice J, Raptis G, Brafman L, Fuentes D, Sierra A, Hershman DL: Prevalence of joint symptoms in postmenopausal women taking aromatase inhibitors for early-stage breast cancer. J Clin Oncol 2007;25:3877-3883.

9 Coleman R: Association between prior chemotherapy and the adverse event profile of adjuvant anastrozole and tamoxifen: a retrospective analysis from the ATAC trial. J Clin Oncol (Meeting Abstracts) 2004;22:abstr 767.

10 Felson DT, Cummings SR: Aromatase inhibitors and the syndrome of arthralgias with estrogen deprivation. Arthritis Rheum 2005;52:2594-2598.

11 Josse RG: Roles for estrogen in bone loss and arthralgia during aromatase inhibitor treatment. Curr Opin Oncol 2007;19:1-8.

12 Blomqvist A: Sex hormones and pain: a new role for brain aromatase? J Comp Neurol 2000;423:549551.

13 Ishizuka M, Hatori M, Suzuki T, Miki Y, Darnel AD, Tazawa C, Sawai T, Uzuki M, Tanaka Y, Kokubun S, Sasano H: Sex steroid receptors in rheumatoid arthritis. Clin Sci (Lond) 2004;106:293-300.
4 Thorne C: Clinical management of arthralgia and bone health in women undergoing adjuvant aromatase inhibitor therapy. Curr Opin Oncol 2007;19: 19-28.

15 Garreau JR, DeLaMelena T, Walts D, Karamlou $\mathrm{K}$, Johnson N: Side effects of aromatase inhibitors versus tamoxifen: the patients' perspective. Am J Surg 2006;192:496-498.

16 Podworny NV, Kandel RA, Renlund RC, Grynpas MD: Partial chondroprotective effect of zoledronate in a rabbit model of inflammatory arthritis. J Rheumatol 1999;26:1972-1982.

17 Akiyama T, Mori S, Mashiba T, Miyamoto K, Komatsubara S, Cao Y, Manabe T, Norimatsu H, Dobashi $\mathrm{H}$, Tokuda M: Incadronate disodium inhibits joint destruction and periarticular bone loss only in the early phase of rat adjuvant-induced arthritis. J Bone Miner Metab 2005;23:295-301.

18 Nakamura T: Approach to pain: effects of alendronate (in Japanese). Itami To Rinsyo 2003:3:333-340.

19 Yamamoto Y, Ohsako T, Hayashi R, Nishimura R, Murakami S, Suzuki S, Shibata Y, Iwase H: Multicenter joint research about joint symptoms with aromatase inhibitors. The 15th Annual Meeting of the Japanese Breast Cancer Society Proceedings 2007;184. 